\title{
THE RELATION BETWEEN COLLECTING DATE AND MATURITY OF RED PINE SEED
}

\author{
By A. S. L. Barnes \\ Ontario Forestry Branch
}

GOR more than ten years the Province of Ontario has been collecting and - extracting all the tree seed necessary for its extensive reforestation projects, involving in the excellent seed year of 1932 the gathering of 40,527 bushels of Red Pine cones alone. For some time it has been felt that the date of picking the cones was one of the most decisive factors in determining the viability and vitality of the seed. In localities where the organized collection of tree seed has been going on for so long one of the greatest problems encountered is that of restraining the people of the community, from whom the seed is bought, from gathering cones before they are ripe and keeping them until the representatives of the Department of Forestry begin buying. Buying of Red Pine cones begins, in Ontario, about the seventh of September and cases have occurred where a single individual has offered fifty bushels of cones on the first day-obviously many of these were collected before the seventh, which was estimated as the earliest date at which it was safe to collect seed.

An intensive survey of Canadian and American forestry literature by the writer has revealed very little information on the relationship between the date of collection and the maturity of tree seed. J. W. Toumey and C. F Korstian* make the following statements:-

1. As the seed matures the outer seed coat usually changes colour and the kernel loses its soft, milky characteristics and becomes firm.

2. Seed collected before maturity is light in weight and after storage the kernel becomes more or less shrivelled.

3. The variation in the weight of clean seed is due chiefly to gathering the seed before maturity and to differences in seed filling, i.e., to shrivelled or undeveloped kernels arising from conditions adverse to satisfactory develop. ment.

4. Seed gathered a short time before maturity is not necessarily infertile, although invariably its viability is impaired and it produces weak and inferior seedlings.

The second and third statements do not seem to be altogether reconcilable with the first since immature seed with a kernel of a soft, milky texture would naturally be expected to contain more moisture and therefore to weigh more than a mature seed which has lost its milky texture and become firm. How ever, it is possible that after a period of storage the kernel of an immature

*Seeding and Planting in the Practice of Forestry-P. 114, 157, 165. 
seed may become shrivelled through more rapid loss of moisture and eventually weigh less than a mature seed stored under identical conditions. The writer's observations on many samples of immature and mature Red Pine seeds have failed to show either a progressive increase or decrease in the weight of seed collected from day to day, before and after maturity of the seed, or even any constant difference between the weight of ripe and unripe seed four months after picking.

C. G. Bates* refers to this subject as follows: "Before I had any personal experience with this species I was told that cones were ripe and might be collected in Northern Minnesota at any time after the 20th of August, or possibly the first of September. This earliest date undoubtedly varies considerably from year to year. I found that cones were still in a very green state on the 9th of September, 1928, and while viable seeds were obtained at this time, at least the collection showed, by its delayed germination, the need of after ripening, and I question whether such seeds will retain their vitality well $-\ldots+$ the 'period of after-ripening' is essentially a drying process - - - but not entirely one of drying."

The period of after ripening is generally accepted as being that period during which either chemical changes occur in the colloidal structure of the seed coat which cause it to become permeable to water and oxygen from without or carbon-dioxide from within, or certain physical and chemical changes, necessary for germination, occur within the embryo. These changes are usually accompanied with, and may be influenced by, the drying process.

As will be shown later, seed collected in Ontario in the fall of 1932 showed no delayed germination whether picked early or late, when germination tests were made two months and four months after picking; and we conclude from these results that the after-ripening period in Red Pine is either quite short (less than 2 months) or that the seed subsequently enters a period of dormancy if the conditions of moisture and temperature necessary for germination do not obtain within a given time. The Ontario Forestry Branch records do not indicate any period of after-ripening or dormancy for this species.

It must be remembered, too, that the seed used in this experiment was collected near the southern limit of the range of commercial stands of Red Pine whereas northern Minnesota is approaching the northern limit and the seed may have entirely different characteristics.

In order to determine the date at which Red Pine, White Pine and White Spruce seed matures in this province and also to determine the effect of the collection of seed before maturity on the seed itself, an extensive experiment was carried out in the fall of 1932 .

*Forestry Chronicle-Vol V.-1929-24. 
For this purpose it was decided to collect fifty cones per day from groups of average seed bearing trees near the seed extracting plant at Angus, which is 11 miles west of Lake Simcoe. (See Fig. 1). Red Pine in this part of Ontario grows only on sand plains, of which there are two of about forty and ten square miles in area, respectively, in the proximity of Angus. The former extends from the village in a south-westerly direction and the latter is about twenty miles to the north on the southern shore of Georgian Bay. The northern area is hummocky, as would be expected in a region formed of sand dunes on

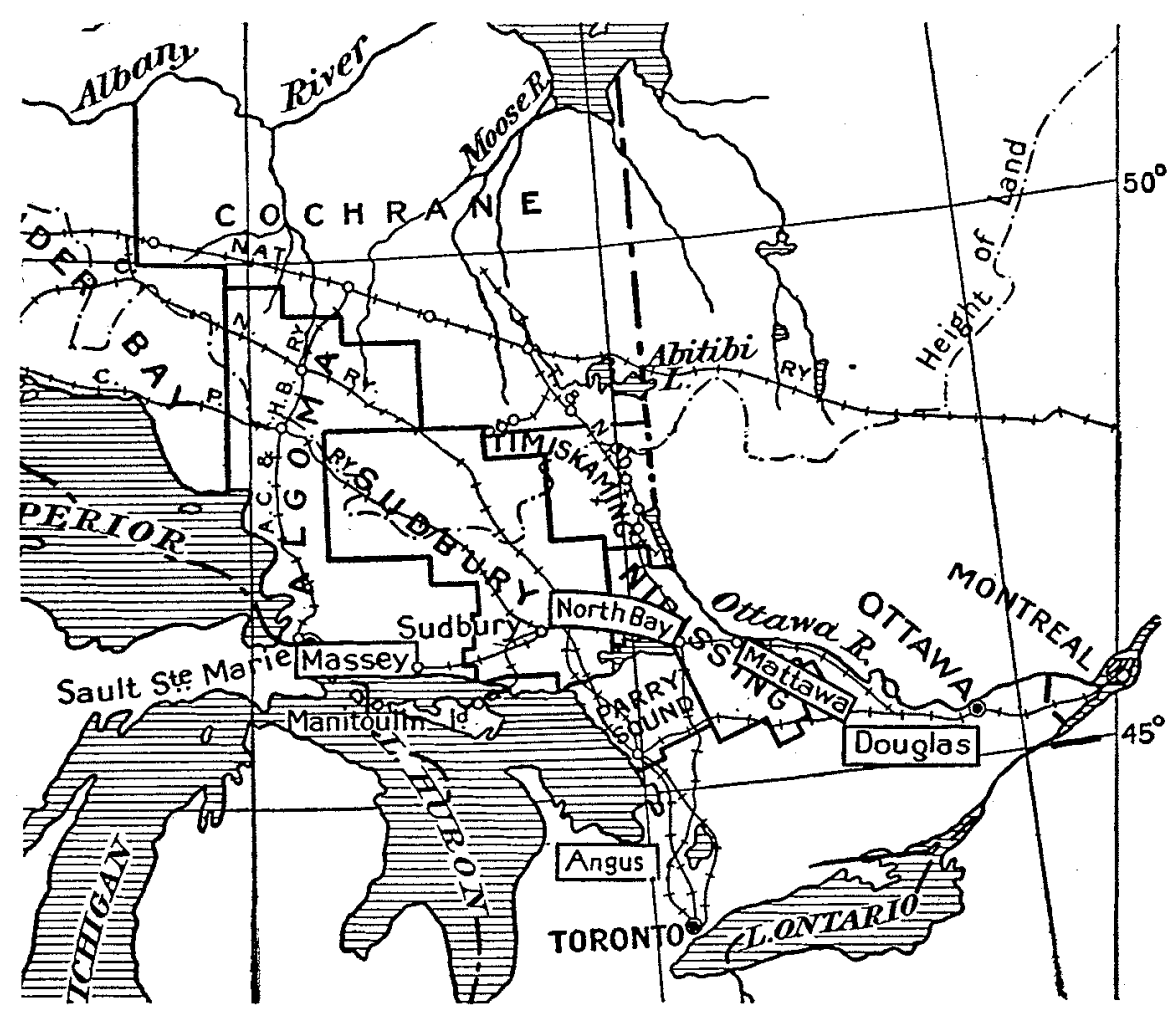

Fig. I.-Showing the geographical position of Angus.

the shore, while the southern area is level, with only gradual changes in contour except where it is intersected by rivers. Four groups were located on the southern plains and three on the northern, one of these latter being within a quarter of a mile of the beach itself and the other two further inland. (See Table I.) Groups of trees rather than individuals were selected in order to ensure a sufficient quantity of cones to last, at the rate of fifty per day, from the twenty-fifth of August until the twenty-fourth of September. The groups consisted of five trees, as a rule, and were watched throughout the daylight hours to make sure that no one, other than the watchman, picked 
the cones. His duty was to pick the fifty cones from each group, the same number from each tree and from all parts of each tree. That is, cones were collected from all the trees and all parts of the crown-top and bottom north, south, east and west sides every day. The trees were all open grown and typical of the specimens from which the majority of the seed is collected.

Red pine is the species of greatest importance both as to the value of the seed, due to indeterminate seed years, and its exceptional value as a tree for reforesting purposes in this province. Seven groups of this species were selected. Four stations, A., B., C. and D., were established, with three groups at $A$, one each at $B$. and $C$., and 2 at $D$. The groups were numbered I., II. and III., and each daily sample was given a number corresponding to the date; for example, the sample collected from group III., station A., on August the 28th was number A III-28. Thus the red pine groups were A I, A II, A III, B I, C I, D I, D II.

Group No.
A I.
A II.
A III.
A
B I.
C I.
D
D
D II.

TAB
RED
No. of Trees
5
5
7
6
12
10
12

TABLE I.

Each day all the samples of cones were taken to Angus and placed in separate compartments of trays in a covered drying shed, with large venti. lators the full length of the shed in the walls. The trays, which were $12 \mathrm{ft}$. $x 4 \mathrm{ft}$., and divided into 64 compartments, were arranged one above the other about one foot apart. The compartments were four inches deep, with a bottom composed of fly screening, fifty cones were placed in each, so that there was a free circulation of air up through them.

The cones remained on the trays, curing under natural conditions of temperature and humidity, during an exceptionally wet autumn, until the first two weeks of November, when extraction was undertaken. The trays were removed one at a time to another building heated by a wood stove. It was found to be impossible to maintain a uniform temperature from floor to ceiling of this building so the trays of cones were heated separately at the same level for twelve hours at temperatures of from $120^{\circ}$ to $130^{\circ} \mathrm{F}$.

Extraction, winging and cleaning of the seed was done by hand. Each sample was shaken in a covered bushel measure to knock out the seed, which was then rubbed over sieves which would permit the passage of the seed without the wings.

The mesh of the sieves used was as follows: 


$$
\begin{aligned}
& \text { Size which } \\
& \text { passed } \\
& \text { all seed }
\end{aligned}
$$

(Used in winging)
Size which

retained

all seed

(Used in cleaning)

Red Pine

$$
12 \times 12
$$

The seed was cleaned by rubbing it over screens which would not pass any seed and by fanning by hand. This latter was accomplished by holding the screen, which had sides three inches deep, at arms length, dropping it quickly about three feet, at the same time drawing it toward the body, then raising

TABLE II.

GROUP A II. (Trees Under 35 Years)

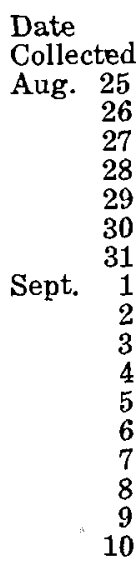
Wt. of
100 seeds Purity
Grs. Total Weight of Seed

$\begin{array}{ll}\text { Grs. } & \% \\ 0.76 & 94 \\ 0.84 & 94 \\ 0.84 & 99 \\ 0.75 & 94 \\ 0.74 & 96 \\ 0.83 & 99 \\ 0.79 & 98 \\ 0.74 & 96 \\ 0.87 & 98 \\ 0.79 & 98 \\ 0.81 & 95 \\ 0.80 & 98 \\ 0.82 & 93 \\ 0.84 & 95 \\ 0.79 & 95 \\ 0.78 & 92 \\ 0.89 & 90\end{array}$

$$
\text { Un }
$$

Uncleaned Cleaned

$$
11.57
$$

$$
12.40
$$

8.61
10.27

10.27

13.48

10.02

12.50

17.35

12.58

11.59

11.03

11.59

8.78

9.58

9.40
7.75

10.90
11.64
8.50

9.65

11.61

13.32

9.84

12.00

17.00

12.30

11.00

10.81

10.78

8.34

9.10

8.84
6.98

No. of

Seeds per

Seeds cone

$\begin{array}{ll}1,435 & 29 \\ 1,388 & 28\end{array}$

1,388

1,012

1,288

1,568

1,603

1,245

1,622

1,957

1,557

1,359

1,352

1,317

1,304

1,151

1,133

28

26

31

32

35

.32

39

31
27

GROUP A III. (Trees over 35 years)

Date

Collected

Aug. 25

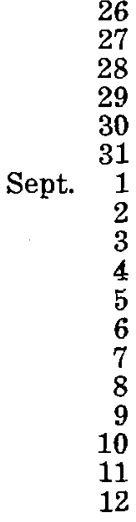

Wt. of

100 seeds

Grs.

0.76

0.80

0.77
0.78

0.78

0.73

0.80

0.70

0.81

0.80

0.83

0.84

0.70

0.75

0.77

0.85

0.83

0.87

0.73

0.74

Purity
$\%$
93
89
96
96
95
91
99
98
98
99
99
99
96
93
97
92
93
94
90

Total Weight of Seed

Uncleaned

13.41

13.71

7.90
8.38

8.38
11.47

13.03

8.42

15.33

11.62

9.33

14.55

10.26

12.29

10.77

13.42

14.84

11.81

8.78
9.47
Cleaned

12.22

7.59

8.04

10.88

11.87

8.34

15.19

11.50

9.22

14.40

11.79

10.00

13.00

13.65

11.00

8.25
8.53
No. of Seeds per

Seeds cone

$1,657 \quad 33$

$1,529 \quad 31$

$986 \quad 20$

1,031

1,489

1,486

1,190

1,875

1,437

1,110

1,716

1,450

1,570

1,300

1,530

1,645

1,266

1,130 


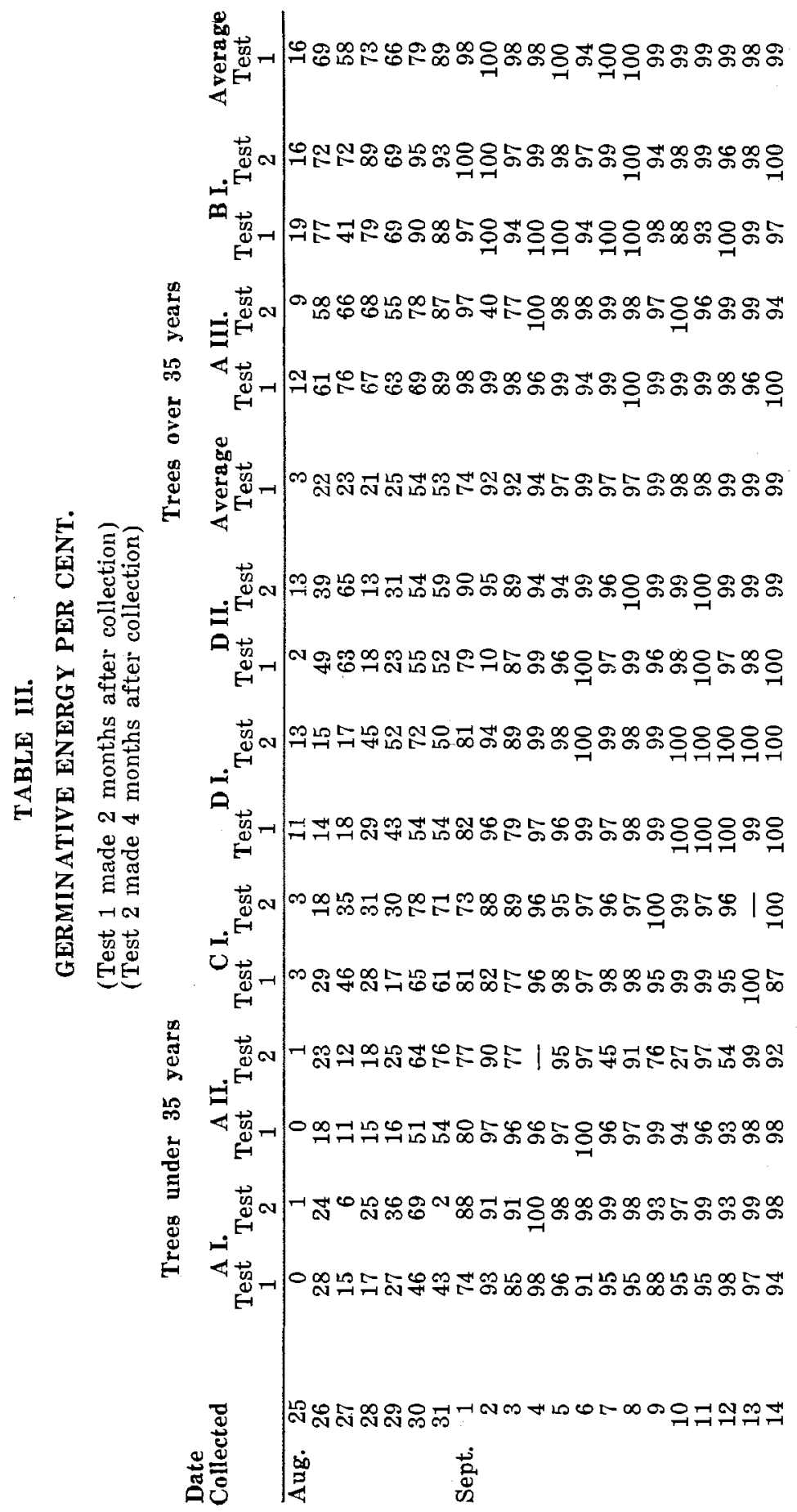


it again and repeating the action with a circular motion. This removed all broken wings and light material without carrying away any seed, even hollow seed was retained.

Each sample of seed was then carefully weighed and tested; tests were made for purity, a physical test was made and germination tests were carried out according to the standard practice at the Angus plant, that is, by the Jacobsen Test as improved by Toumey. The germinative energy period is fixed at 30 days for red pine. Tables II. and III show the results obtained.

When the cones arrived at Angus it was impossible to tell from their outward appearance which were picked before maturity and which after, but as the curing proceeded, the red pine cones picked after September the third turned to the natural rusty red colour, whereas those picked before September the third turned a dirty, olivergreen shade, with a distinct shrivelled appearance to the cone scales. This was quite apparent in cones from all seven stations with a. gradual change of colour from August 28th to September the third. In addition, the seed was more difficult to extract from cones picked too early.

During the time that heat was being applied it was noticed that the cones picked later opened more readily than those picked early.

Physical tests revealed nothing, seed collected before maturity looked exactly the same as that collected later, no constant increase in shrivelling or rancidness of the kernel could be detected. Physical tests did show, however, a fair proportion of empty seeds in all samples indicating that the method used in cleaning did not remove these seeds and thus bring all samples to a somewhat uniform degree of quality as is the case when mechanical fanning methods are used for cleaning.

It was thought that tests for purity might reveal some relationship between the readiness of the cones to open and the degree of impurity, since it is usually found that cones which are difficult to open produce a lot more foreign matter with the seed, due to their breaking up more during the process of extraction. The crude methods of cleaning used in this experiment, however, produced variations in the degree of impurity of the samples which effectually obscured any relationship which may have existed.

The total weight of cleaned seed from each daily sample of cones was computed in order to determine whether cones picked after maturity would yield more seed than those picked before, due to their greater readiness in opening, but comparison of the results showed no constant difference and indicated that all samples had been completely opened during extraction, differences in weight of seed being due to different quantities of seed present in the cones. Counts revealed that cones externally the same in every respect -J. W. Toumey and C. F. Korstian-Seeding and Planting in the Practice of Forestry-Pa'se
182. 
may contain any number of seeds from two in comparatively rare instances to fifty.

The weight of 100 seeds from each daily sample was recorded, but as previously stated, no difference in weight was found between mature and immature samples. (See Table II).

Germination tests on each daily sample of seed were made approximately two months after the date of collection, one hundred seeds were used in each case and the whole 200 tests set up side by side as quickly as possible, so as

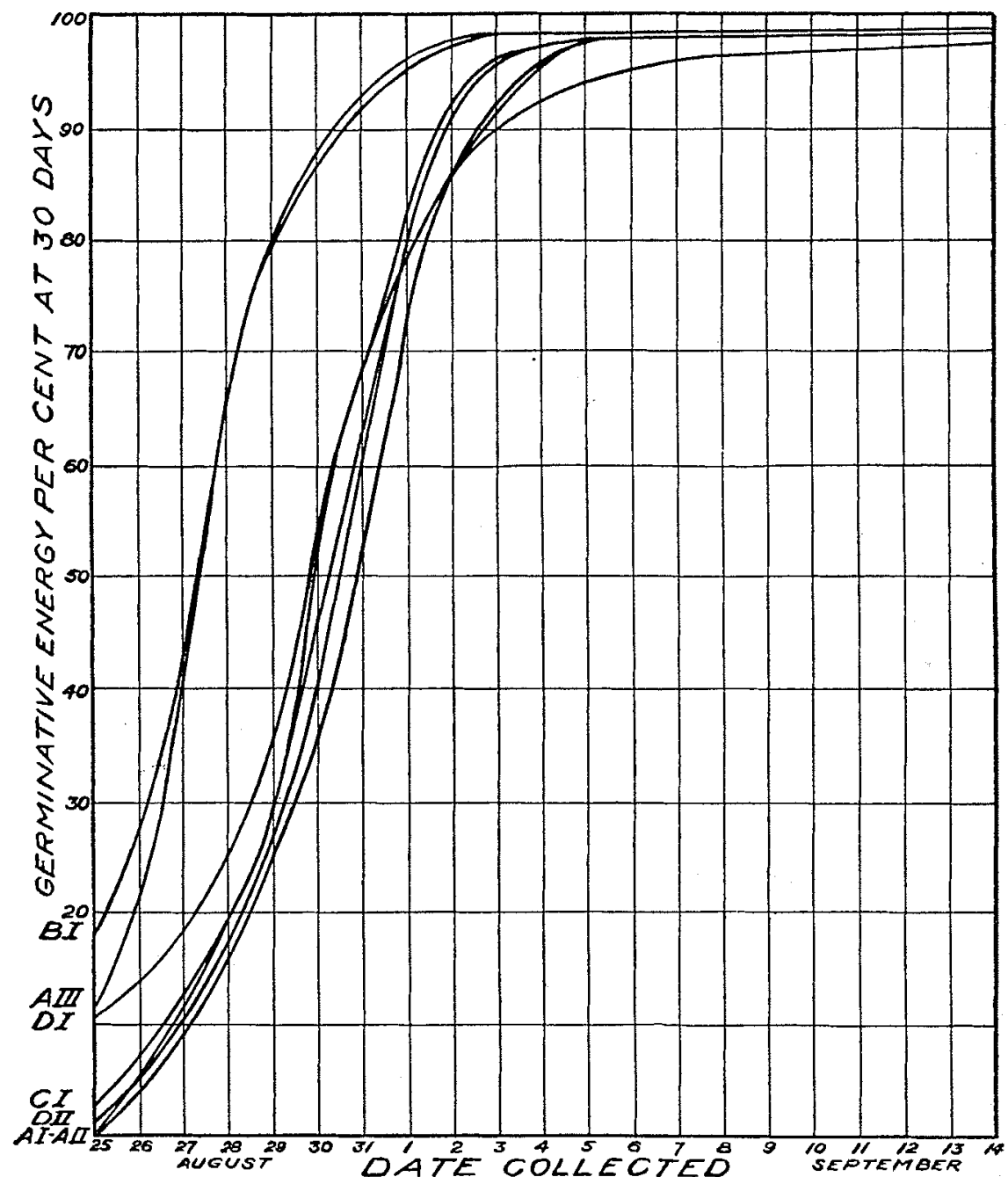

Fig. II-Showing the degree of ripeness of daily samples as indicated by germinative energy per cent. 
to give the greatest degree of uniformity, and the opportunity for direct comparison.

It was here that the difference between the daily samples was really demonstrated, not only did the mature samples show a higher germinative energy per cent, but they showed a distinct progressive rise from day to day with the most rapid rise from August the twenty-fifth to September the second, after which the rate of increase in germinative energy declined until a maximum of 99 per cent was attained. Not only did the mature samples show a higher germinative energy, but maximum germination was reached in a much shorter time; some mature samples reached 100 per cent in ten days, while many were over 95 per cent in this time, whereas immature samples spread their dribbles of germination over nearly the whole 30 days. During the time the tests were in progress, the almost complete absence of mould from the mature samples was very marked, especially in the case of those which reached a high percentage in a very short time. The immature samples, on the other hand, showed a very distinct gradation in the amount of mould in inverse ratio to the germinative energy per cent and the rate of germination, that is mould appeared early in the test, on the samples of seed picked early and rapidly covered the lot with a dense mat of mycelia. The difference in the amount of mould was so marked that after the removal of the seed and the filter paper on which they had lain, the position the different daily samples had occupied on the underlying felt could be determined by the degree of discolouration and disintegration of the felt by the mould which had appeared on the seed.

During the germination tests seeds were removed periodically as they germinated and an examination of the remainder afterwards showed that the great majority of the kernels of seeds from the early samples were brown in colour, slimy in texture and rancid, whereas those from mature samples were mostly hollow or had shrivelled kernels, which precludes the possibility of delayed germination at this stage. When the curve germinative energy per cent over date of collection was plotted it was found that the seed from older trees gave different curves from the seed from younger trees, the upper two representing trees over 35 years old and the lower 15 trees under 35 years (Fig. II). Table III. shows the results of germination tests made two and four months after the collection of the seed.

Figure III. illustrates the greatly increased rate of germination of seed collected on later dates. Counts of the number of seeds germinated were made from the ninth day to the fifteenth day after germination and the samples illustrated were picked at random from the daily lots of group A. II. These curves are based on figures from tests made four months after collection (Test 2) which consistently corroborated the figures obtained by the previous test. 
(Test I). The variation in the germinative energy per cent figures was only rarely greater than $3 \%$ in samples collected after September the fourth. (Table III.)

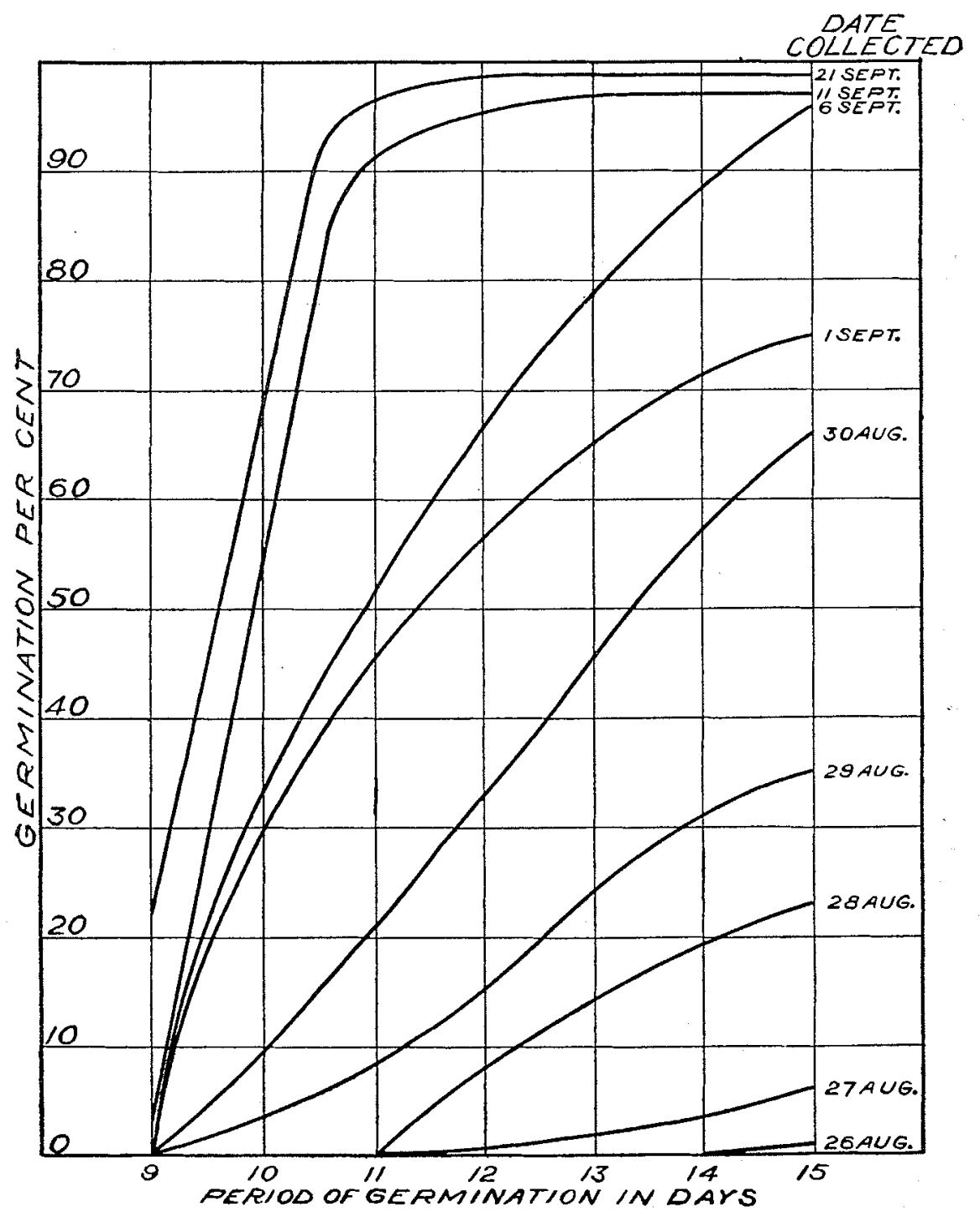

Fig. III.-Showing rate of germination of various daily samples.

There is no doubt that the date of maturity of the seed is determined in part by weather conditions and varies somewhat from year to year on this account. It is probable that the weather immediately preceding the ripening clate exerts the greatest influence and that the conditions of temperature and 
especially humidity are the chief factors concerned, since maturing of seed is largely a drying process. Frost plays no part in the ripening of red pine seed in this locality since the earliest recorded frost is Sept. 9, and even then only $3^{\circ}$ of frost were recorded, and the average about October 4.

The following table gives a comparison of the weather data figures at Angus for August and September, 1932, with the means for Barrie, only 11 miles distant, over a period of 45 years for the same months:-

\begin{tabular}{|c|c|c|c|}
\hline \multicolumn{4}{|c|}{ Monthly Averages of Normal Daily } \\
\hline Max. & Min. & Mean & Rainfall in inches \\
\hline 79 & 53 & 66 & 5.64 \\
\hline 75 & 56 & 66 & 2.71 \\
\hline 72 & 46 & 59 & 7.59 \\
\hline 69 & 50 & 60 & 2.57 \\
\hline
\end{tabular}

August, 1932

Mean of 45 yrs.

September, 1932

69

60

2.57

It will be seen from the above records that the mean temperatures for both August and September are very close indeed to the average of the means for 45 years and also that the deviation from the maximum and minimum figures is not great. So that, in respect to temperature at the time of seed maturity the year 1932 was a normal year. If we now examine the figures for precipitation during this same period we find that both months were exceptionally wet, August receiving twice and September almost three times their normal rainfall. Of the total of 7.59 inches for September 3.63 inches fell before the eighth, which the germinative energy curve indicates as the date on which all the seed had ripened, adding this to the rainfall for August we find that in the 39 days prior to the eighth there was 9.27 inches in 1932 as compared with a normal precipitation of 3.57 inches for same period. Since humidity during this period is the chief meteorological factor in deter. mining the date of ripening of seed it is probable that we have determined the latest date on which Red Pine seed matures.

It is obvious, however, that further experimental work will be necessary to correlate the date of maturity with weather conditions so that it can be prophesied with accuracy.

Germination tests on white pine and white spruce indicate that the experiment was started too late for these species, most of the seed being ripe by August the twenty-fifth.

SUMMARY OF RESULTS.

1. It is impossible to tell from the external appearance of Red pine cones whether they have been picked too early until they have cured for some time, when the immature cones turn a dirty, olive-green colour and the cone scales appear shrivelled on the outside surface, whereas mature cones turn a rusty red colour and scales do not appear shrivelled. 
2. There is no appreciable difference between the weight of mature and immature seed of red pine within four months after collection.

3. If red pine seed is germinated within four months of collection there is no delayed germination in either mature or immature seed.

4. Some seed matures earlier than other seed, the period from the matur. ing of the first seeds to the maturing of the last seeds being about 15 days for red pine seed in 1932 .

5. Seed from trees over 35 years of age matures 3 to 4 days earlier than that from younger trees.

6. Immature seed turns rancid and rots when subjected to the conditions of moisture and temperature necessary for germination causing a tremendous increase in the amount of mould which occurs during germination tests.

7. The latest date on which red pine seed matures at the southern limit of commercial stands of this species is probably September the tenth.

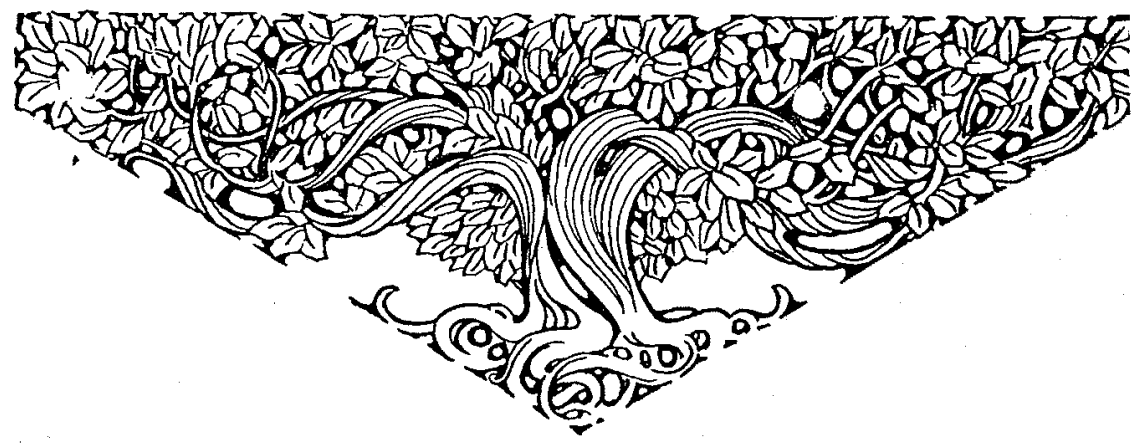

